Making meaningful comparisons between road and rail - substituting average energy consumption data for rail with empirical analysis

Mr. James Pritchard

Prof. John Preston

Dr. John Armstrong

Transportation Research Group, University of Southampton, Southampton, United Kingdom

Transportation Research Group

Civil, Maritime and Environmental Engineering and Science Unit Engineering and the Environment

University of Southampton

Highfield Campus

Southampton SO17 1BJ

j.a.pritchard@soton.ac.uk

+44(0) 7789267259 


\title{
Making meaningful comparisons between road and rail - substituting average energy consumption data for rail with empirical analysis
}

\author{
Within the transport sector, modal shift towards more efficient and less polluting \\ modes could be a key policy goal to help meet targets to reduce energy \\ consumption and carbon emissions. However, making comparisons between \\ modes is not necessarily straightforward. Average energy and emissions data are \\ often relied upon, particularly for rail, which may not be applicable to a given \\ context. Some UK train operating companies (TOCs) have recently fitted \\ electricity meters to their trains, from which energy consumption data have been \\ obtained. This has enabled an understanding to be gained of how energy \\ consumption and related emissions are affected by a number of factors, including \\ train and service type. Comparisons are made with existing data for road and \\ rail. It is noted that although more specific data can be useful in informing policy \\ and making some decisions, average data continue to play an important role \\ when considering the overall picture.
}

Keywords: energy; carbon; rail; modal shift

\section{Introduction}

The UK Climate Change Act 2008 established a legally binding target to reduce greenhouse gas (GHG) emissions relative to 1990 by at least $80 \%$ by 2050 and a system of carbon budgets has been introduced to help meet it (HM Government, 2011). Emissions from the UK transport sector increased by 13\% between 1990 and 2009, whilst the UK's total GHG emissions have fallen by about $25 \%$ over the same period (Department for Transport, 2011). The net result is that in 2009, transport emissions accounted for $27 \%$ of the UK's GHG emissions, up from $18 \%$ in 1990 . From the transport sector, almost all direct GHG emissions are in the form of carbon-dioxide $\left(\mathrm{CO}_{2}\right)$ (Department for Transport, 2009). Indirectly, domestic transport additionally contributes to overall emissions levels through the consumption of electricity, the generation of which also produces GHG emissions. In 2010, the transport sector 
accounted for $1 \%$ of electricity demand in the UK (Department of Energy \& Climate Change, 2011, Chart 5.1)

Car travel accounts for over half of the GHG emissions from domestic transport in the UK (in 2009, the figure was 58\%, Department for Transport, 2011). This reflects both the dominance of the car as a mode of transport and the reliance on the internal combustion engine (ICE). In 2012, 64\% of all passenger trips in the UK were made by car, either as a driver or passenger (Department for Transport, 2013), and alternativelyfuelled vehicles (AFVs) - those which are not powered solely by a petrol or diesel ICE - accounted for just $1.4 \%$ of the new car market. In recent years, motor manufacturers have invested heavily in more efficient models, due in part to European Union regulations; in 2012, average $\mathrm{CO}_{2}$ emissions for new cars were $26.5 \%$ lower than those in 2000 (SMMT, 2013). Despite these trends, it is argued that technological innovation alone is not enough, and that "significant reductions of $\mathrm{CO}_{2}$ emissions in transport in the EU can only be achieved through behavioural change" (Banister, 2010, p3). Such behavioural change may include modal shift towards lower polluting modes - for example, from road to rail. As it stands, rail's modal share is comparatively small, with only 3\% of passenger trips in 2012 being made by train (Department for Transport, 2013). However, rail's contribution to GHG emissions is smaller still, with only $1.8 \%$ of the UK's domestic transport GHG emissions being directly assigned to rail in 2009 (Department for Transport, 2011). As Armstrong \& Preston (2010, p3) put it, "rail’s specific strengths in the context of climate change include its general environmental friendliness relative to competing modes." The basis for this includes the fact that for steel wheels running on steel rails there is comparatively little rolling resistance, which results in greater energy efficiency, and thus a potential reduction in emissions. 
Making comparisons between road and rail, however, is not straightforward. Data for rail are comparatively scarce, and journey comparison tools, such as Transport Direct (www.transportdirect.info) often rely on average data, such as that provided in the UK by the Department for Food, Environment \& Rural Affairs (DEFRA). The Rail and Safety Standards Board Ltd. (RSSB, 2007, p37) suggest that "mixing the results for unspecified services with very different characteristics makes the final figure of limited value and the results are always open to challenge." Although it could equally be argued that it is meaningless to isolate a single service from a complicated system, it is nonetheless beneficial to understand how energy consumption and hence emissions vary across different train and service types.

Specific data which are available are often based on simulations rather than empirical observation and may in any case be subject to a variety of assumptions. As a result, published data for a single type of train can vary significantly. However, in recent years, some UK Train Operating Companies (TOCs) have begun to equip their electric trains with meters, in order to monitor consumption, thus generating comprehensive empirical data. As of May 2013, around 20\% of rail traction electricity consumption in the UK is now billed on the basis of actual measured data (Network Rail, 2013).

Following a brief review of some of the existing data for both road and rail, and the associated limitations, analysis of some metered data is presented. Data provided by two TOCs are used to calculate energy consumption for a variety of electric trains, in terms of kWh per seat-km. Although such analysis is necessarily limited to electric trains, it is nonetheless useful for investigating the possible variation in the energy consumption of a train over different routes and service-types. The metered data has also been used to estimate the proportion of the energy consumed which might be 
attributable to the 'hotel load' - the energy required to power on-board services, such as heating, ventilation and air-conditioning (HVAC) systems and lighting. The benefits of regenerative braking systems are also apparent.

Published data about the carbon intensity of the UK electricity grid are then used to calculate estimated $\mathrm{CO}_{2}$ emissions figures for the electric trains for which energy consumption data were analysed. Modal comparisons typically use a metric based on passenger-km, and occupancy data are therefore required. $\mathrm{CO}_{2}$ emissions from road and rail are compared, for varying load factors (level of passenger occupancy). A discussion focussed on making modal comparisons follows, highlighting what can be learned from having more specific data and what really should be taken in to account when comparing the different modes.

\section{A brief review of existing data}

\subsection{Average data published by DEFRA}

The Department for Food, Environment \& Rural Affairs (DEFRA), provides estimated average emissions data for different modes of transport (Department for Environment Food and Rural Affairs, 2013a, 2013b), which can be used as a basis for modal comparisons. For example, the online journey planner and carbon calculator Transport Direct (www.transportdirect.info) makes use of this data set when estimating the carbon emissions of a particular journey. This section summarises the methodologies used to obtain some of the figures for passenger road and rail transport and discusses the limitations of the data.

\subsubsection{Emissions from passenger cars}

DEFRA provide a set of estimated $\mathrm{CO}_{2}$ emissions figures for passenger cars in the UK. 
This includes an overall average for petrol cars, an overall average for diesel cars, and an average figure for each market segment. The data are presented in terms of $\mathrm{CO}_{2}$ emissions (in grams) per vehicle-km. A more usual metric for making modal comparisons is $\mathrm{CO}_{2}$ per passenger-km, which can be derived from the data per vehicle$\mathrm{km}$ simply by dividing by the number of occupants in the car. In the UK, it is suggested that the average car journey is made by 1.6 people (including the driver), which corresponds to a load factor of $32 \%$ in a car with five seats (RSSB, 2007)

When making a car journey, private individuals are not required to log fuel consumption or emissions data. Hence in order to estimate average passenger car emissions, DEFRA rely on official emissions figures from the manufacturers, along with sales data to estimate the make-up of the UK car fleet, and data from Automatic Numberplate Recognition (ANPR) cameras to weight the emissions factors to account for the age and activity distribution of the fleet (Department for Environment Food and Rural Affairs, 2013b).

It is recognised that the New European Driving Cycle (NEDC) used in European vehicle type approval tests to produce official fuel consumption and $\mathrm{CO}_{2}$ emissions levels is not representative of real-life driving conditions (Mock, German, Bandivadekar, \& Riemersma, 2012). Additional 'real-world' effects include, amongst other things, cold-starting, gradients, varying rates of braking and acceleration and poor vehicle maintenance. To account for these, an uplift of $15 \%$ over the official NEDC values was agreed with the Department for Transport (DfT) in 2007, and has been included in the data published in recent years by DEFRA $(2010,2013 \mathrm{~b})$. The validity of this uplift factor has been recently called in to question (Department for Environment Food and Rural Affairs, 2013b) and is briefly discussed further in Section 2.2.1. 


\subsubsection{Emissions from passenger rail}

For public transport modes, emissions data are presented by DEFRA on a per passenger-km basis. Three sets of rail data are given; data for international rail (Eurostar), data for national rail (the main UK heavy rail network) and data for light rail. Although all three could to some extent be a reasonable alternative to the car, the focus in this paper is on national rail. The main reason for this is that the empirical data analysed in Section 3 pertains to trains on the national network, but it is also worth noting that modal shift to national rail is less context specific (modal shift to Eurostar is only relevant for journeys to Europe, whilst modal shift to light rail is mainly only applicable to urban centres).

DEFRA publish a single $\mathrm{CO}_{2}$ emissions figure for national rail. It is based on the amount of electricity and diesel consumed by the railways in a given year (sourced from the Association of Train Operating Companies) and the total number of passenger$\mathrm{km}$ travelled in the same period (sourced from national rail Trends) (Department for Environment Food and Rural Affairs, 2013b). It is assumed that this figure relates only to train operations and does not include infrastructure, but that it includes all necessary overheads such as idling and running empty trains to and from the depot.

\subsubsection{Emissions from buses and coaches}

It is worth making mention of buses and coaches because when considering road and rail transport they are often a viable alternative to the car or train. DEFRA's $\mathrm{CO}_{2}$ emissions figures for buses are calculated in a similar manner to those for national rail namely they are based on the amount of fuel used by the bus operators and passenger occupancy statistics (both provided by the DfT) (Department for Environment Food and Rural Affairs, 2013b). Local bus data is subdivided to separate London from the rest of 
the country, to reflect much higher passenger occupancy levels in the capital. Data for coaches are based on figures provided by National Express, who provide the majority of scheduled coach services within the UK, but the passenger occupancy data are combined with that for non-local buses. Actual occupancy levels for coaches are thought to be significantly higher (and correspondingly, the emissions per passenger figure should be lower).

\subsubsection{Limitations of average data}

Average data can be useful for considering overall trends. However, a key limitation of average emissions data, such as that provided by DEFRA, is that it doesn't differentiate between different journey types, let alone specific journeys. This makes it hard to discern the contexts in which modal shift (from road to rail, for example) should be most encouraged, and whether there are some circumstances which buck the average trends.

One of the differences between car travel and public transport modes is that for public transport the choice of vehicle is typically much more closely linked with a particular journey; in contrast, a car driver is likely to use the same vehicle for making a range of journeys. DEFRA's provision of data for different vehicle segments, and the availability of NEDC data (discussed further in Section 2.2.1) makes it comparatively easy to separate out the variation between car models when considering more specific scenarios. Similarly, data are available which can be used to infer how emissions might be expected to vary for journeys with different characteristics (for example by considering the different components of the NEDC).

On the other hand, the use of a single $\mathrm{CO}_{2}$ emissions figure for national rail travel is particularly limiting, because the rail network in the UK is diverse. The range of passenger operations includes commuter services, rural and regional services and 
higher speed intercity services, with provision for fairly local and long distance travel. The potential for variation is significant, even before the differences between diesel and electric trains are considered, which is why the opportunity to analyse empirical data from electric trains (Section 3) is thought to be beneficial.

When it comes to data presented in terms of emissions per passenger-km, it is important to note that real world passenger occupancy levels (the load factor) can be quite variable. Car occupancy levels vary according to the purpose of the trip made, with an average occupancy level of 1.12 people for business trips and commuting in the UK in 2012, rising to an average of 2.0 for leisure trips and education (Department for Transport, 2013). Load factors on public transport can also vary between different service types, which is why DEFRA have made some attempt at separating local buses and coaches (Department for Environment Food and Rural Affairs, 2013b), and their consolidation of non-local buses and coaches is questionable. For rail, the RSSB (2007) suggest that the average load factor for regional, suburban and local services is around $30 \%$, rising to $40 \%$ or more for intercity services. High speed services often have higher load factors, a fact noted by Network Rail (2009), who suggest that typical load factors for European high speed rail services range from $42 \%$ to $88 \%$; they are lowest for the German ICE services which operate higher frequencies over shorter distances, and highest on French TGV services where the cities are further apart.

Public transport load factors can be particularly susceptible to temporal variations (for example, morning peak services towards an urban centre might be expected to be particularly crowded). They are also thought to be more susceptible to changes during a particular journey than a journey made by car might be expected to be, because bus and train passengers do not always travel the entire length of the route (it is noted, however, that car drivers may also only carry passengers for part of a journey). 
Possible effects of varying the load factor when comparing the emissions of different modes have already been highlighted by Chester \& Horvath (2009), and are considered here in Section 5.

\subsection{More specific data for each mode}

In addition to average emissions data for each mode, such as that published in the UK by DEFRA, a range of more specific data are available. This section aims to give an overview of the sort of data which are typically available and discusses some of the associated limitations.

\subsubsection{Specific data for road transport}

When it comes to cars, obtaining data for a particular make and model is comparatively easy, especially within the European Union, where emissions test data are published by the manufacturers. The advantage of the New European Drive Cycle (NEDC) tests used to obtain this data is that they are performed in a controlled environment, meaning that a fair comparison can theoretically be made between different cars. The main disadvantage, as noted in Section 2.1.1, is that the resulting data are not necessarily representative of the real world. Indeed, the differential between the NEDC values and the actual $\mathrm{CO}_{2}$ emissions of cars on the road appears to be widening (Department for Environment Food and Rural Affairs, 2013b). This is corroborated by several studies, including that undertaken by Mock et al. (2012), who compared NEDC data with two alternative German data sources. The consensus seems to be that by 2011 , the discrepancy between the test data and real-world driving was more than $20 \%$, with some, such as Patterson et al. (2011) finding that for hybrid vehicles it typically exceeds $30 \%$. 
Example fuel consumption data for specific types of bus and coach are provided by the RSSB (2007), from which it is possible to estimate $\mathrm{CO}_{2}$ emissions (the RSSB use a conversion factor of $26.5 \mathrm{~g} \mathrm{CO}_{2}$ per litre of diesel per $\left.100 \mathrm{~km}\right)$. The data are based on a number of routes operated by Stagecoach, but it is not possible to infer anything about the characteristics of the routes and whether the fuel consumption data would be equally applicable elsewhere. It is also not clear how the specific models of bus analysed compare with similar models used by other operators, whilst at least one of the models would appear to be quite old even at the time the report was compiled (the age of the Dennis Trident fleet is given as about 15 years back in 2007). The small sample size two of the sub-fleets considered are said to comprise less than 20 buses - should also be noted.

The biggest problem remains estimating the emissions on a per passenger basis for a given bus journey - whereas the number of occupants of a car might reasonably be expected to be known when planning a journey, issues arising when estimating the load factor for a given bus journey have already been discussed. The RSSB considered both data for the UK as a whole and that from specific contexts in the North West, and suggest that a typical local bus has nine passengers. This is comparable to the data given by DEFRA (Department for Environment Food and Rural Affairs, 2013b), who suggest a figure of 9.5. Despite this, the RSSB conclude that this average figure includes routes which are not comparable with the train as an alternative mode of transport - following their example, local buses will not be considered further in this paper. For coaches, the RSSB considered a study of Victoria Coach station, which concluded that on average the load factor was $60 \%$ (about 40 passengers/coach). This is potentially helpful when considering the specific scenario of traffic to/from London, but it may not reflect coach travel overall. The national average might be expected to be lower, because of Victoria 
Coach station's position as a key interchange and the fact that the study included international departures, although the data does match the data for coach travel in Germany (60\%) (European Environment Agency, 2010). Overall, the European Environment Agency suggest that on long distance buses and coaches, an average of $33 \%$ of the seats are occupied, but, like the data for the UK presented by DEFRA, this may not be especially applicable in a more specific context.

\subsubsection{Specific data available for rail}

Although DEFRA use an average emissions figure for the whole UK rail network, specific data for individual types of train are available. Key sources include reports produced by Hobson \& Smith for AEA Technology (2001) and by the Rail Safety and Standards Board (RSSB, 2007). Network Rail (2009) have also published some data about intercity and high-speed electric trains, both in the UK and abroad. However, the data are based on a range of simulations and limited empirical findings, and are not directly comparable. For example, of the 37 electric trains and locomotives considered by Hobson and Smith, energy consumption data for 12 of them are theoretical values based on a flat route with a given stop spacing, whilst the remainder are based on limited empirical data. The empirical data are based on a small number of real journeys (a single journey in one case) or assumptions that different train types can be classed as similar for these purposes.

The problem with small sample sizes can be illustrated by comparing Hobson \& Smith's empirical data for the Class 390 'Pendolino' train ("14 journeys to/from London Euston") with the measured data collected by the RSSB for journeys between Euston and Manchester. In terms of energy consumption per seat-km, Hobson \& Smith's data equates to $0.041 \mathrm{kWh}$, which is about $28 \%$ higher than the $0.032 \mathrm{kWh}$ suggested by the RSSB. Reasons for the variation may include differences in the 
services studied (in terms of route, time of day and passenger loading) and the fact that small sample sizes are susceptible to the effects of perturbations and delays. The RSSB acknowledge that service patterns and the number of station stops are likely to have an impact, for example, when comparing the similar Class 221 and Class 222 intercity diesel trains, but do not attempt to quantify this further. The scope of the empirical measurements is also unclear; it could be assumed that the measurement of fuel usage for diesel trains includes at least some of the additional overheads associated with running a train service, such as idling between journeys, whilst the monitoring of individual journeys for some electric trains does not.

The use of simulations avoids some of the problems associated with empirical data and makes it possible to compare different types of train on the same basis. The downside is that some factors, such as gradient, are rarely accounted for, whilst assumptions have to be made about various different aspects, including driving style, and the net result may not reflect reality. A good example of this is the data collected by Network Rail, which are a combination of simulated and empirical findings, and are based on the maximum in-service speed of the trains in question (Network Rail, 2009, Table 2.5).

As with other modes of public transport, specific emissions data for individual vehicle types only helps provide part of the picture. To consider specific scenarios on a per passenger basis, it can be helpful to have a more detailed understanding of passenger occupancy levels. Data from the Office of Rail Regulation (2011) can be used to estimate mean passenger loadings for each of the UK Train Operating Companies (TOCs) individually, and also includes a look at the variation with time in the number of passenger numbers arriving and departing key urban centres. It should be noted, however, that many TOCs operate a wide variety of different services, and so any 
estimations made on this basis may still be considered to be quite generic. This is why the modal comparisons in Section 5 consider a range of load factors.

\section{Analysis of energy consumption data from electric trains in the UK}

\subsection{A summary of the data made available for this research}

\subsubsection{Data from an intercity train operating company (TOC)}

An intercity operator provided two years' worth of metered energy consumption data for their fleet of trains. This included energy readings for each train, taken at five minute intervals and assigned a timestamp and a GPS location. Additional data from the On Train Monitoring Recorders (OTMR) were provided, along with records of the routes and schedule allocations for each train in the fleet.

\subsubsection{Data from a suburban TOC}

A suburban operator provided metered energy consumption data covering a one month period for its fleet of electric trains. Data for three classes of train were included, which are referred to here as "Suburban Electric A", "Suburban Electric B" and "Suburban Electric C". They are described along with the intercity train analysed in Table 1.

The data provided included energy readings for each train, along with a timestamp and a GPS location. The energy readings were taken at the higher rate of one every minute, but no additional OTMR data were made available in this case. Data linking each energy reading to a particular service allocation were provided.

\subsubsection{Data about the UK rail network}

Geographic Information System (GIS) data giving the locations of the lines and stations which comprise the UK rail network were downloaded from the ShareGeo Open Source 
Repository (ShareGeo, 2010). Additional information about the Timing Information Point Locations (TIPLOCs) used for train schedules was also obtained, including known mileage data between key points (swlines Ltd., 2012).

\subsubsection{Rail scheduling data}

Extracts from Network Rail's Train Service Database were obtained (Network Rail, 2012), which adhered to the Common Interface File (CIF) standard (Network Rail, 2007).

\subsection{Main Stages of Analysis}

Microsoft SQL Server was used to store the data, and queries were written to perform the bulk of the analysis. Other software, including ArcGIS and Google Earth for mapping, and Python, was used where appropriate.

\subsubsection{Mapping of the metered energy data to the UK Network}

It can be reasonably assumed that each of the trains for which data are held were running along the railway lines which make up the UK network. To help identify GPS measurement errors and to verify the allocation of a train to a given schedule, each energy reading was mapped to the nearest point on the UK network.

Mapping software (ArcGIS 10.1 and Google Earth) was used to define the network as a set of closely spaced points, and a point matching algorithm was written in Python to find the nearest network point for each energy reading. In addition to the nearest network point, outputs included the matching error (the distance between the energy reading and the point on the network) and data about the nearest TIPLOC, depot and weather station for which historical data had been obtained from Weather Underground (Weather Underground Inc., 2013). 
GPS data which purported to be outside a given region covering the relevant part of the UK network were excluded from the output as the data could reasonably be assumed to be erroneous.

\subsubsection{Identification of potentially erroneous energy readings}

Energy readings from the intercity operator included a 'Record State' for each meter which was marked as 'NO' if the reading was suspected to be anomalous and ' $\mathrm{OK}$ ' otherwise $-78 \%$ of the supplied readings were ' $\mathrm{OK}$ '. Readings from the suburban operator included a set of 8-bit integers (each with a positive value range of 0 to 127 ) to indicate the quality of each meter reading and GPS location. A score of 127 implied complete confidence in the data $-98 \%$ of the energy data had a quality score of 127 and were marked 'OK' accordingly.

\subsubsection{Labelling of energy readings according to time period.}

Each energy reading was labelled according to the time period in which it was taken. The time periods were chosen as follows:

- Weekend: Saturday and Sunday between 6am and 11pm

- Morning Peak: Weekdays between 7am and 10am

- Evening Peak: Weekdays between $4 \mathrm{pm}$ and $7 \mathrm{pm}$

- Off Peak: Weekdays between 6am and $11 \mathrm{pm}$ but outside the peak periods

- Night: Between 11pm and 6am

\subsubsection{Matching of each allocated service to a schedule and route}

Scripts were written in Python to convert the timetable data from CIF format in to a set of data tables which could be easily referenced. Each different schedule was assigned a unique integer ID. A route finding algorithm was developed to estimate the distance for 
each schedule, along with the distance between stops. The allocation data provided by each TOC was then linked to a particular schedule.

Each train service has a train reporting number, also known as a headcode, which was provided by the TOCs in the allocation data. The headcode is a four digit alphanumeric code which can also be used to identify the type of service (for example, trains in passenger service typically have headcodes starting with ' 1 ' or ' 2 ' and trains running empty to/from a depot or siding have headcodes starting with ' 5 '). The headcode is not unique for each schedule in Network Rail's Train Service Database for example, a weekend service may have the same headcode as a weekday service, even though the timings and stopping patterns may differ. Hence in order to match a TOC allocation to a given schedule, the timings of the allocation were also considered. In some cases, where there was potential doubt about the reliability of the data, the observed location of the train was checked against the scheduled origin and destination. Services which did not depart and arrive within 10 minutes of the scheduled times were excluded.

\subsubsection{Identification of stationary points and estimation of the hotel load.}

Having matched each energy reading to a point on the UK network, each energy reading for a given train was compared with the one preceding it. If the matched network point had not changed, the reading was assumed to cover a period when the train was stationary, and was marked as such. Stationary points located in or very close to a known depot or siding were then relabelled as 'Depot.'

Stationary readings were used to estimate the 'hotel load', which is the energy used to power on-board auxiliaries and 'comfort functions' such as heating and lighting. It was assumed that when an electric train is stationary, the hotel load is the prime source of energy consumption. Estimates for the hotel load were calculated on a kWh per 
minute basis. Data labelled as 'Night' or from when the train was known to be in a depot were excluded. It was postulated that the hotel load is dependent on ambient temperature. Temperature data were extracted from historical weather data (Weather Underground Inc., 2013) and for each class of train estimates of the hotel load for a given journey were checked against the overall average observed at that temperature. Any estimate of the hotel load which was not within one Absolute Deviation of the Median for a given temperature was excluded.

\subsubsection{Estimating energy consumption}

For each allocated service, it was possible to calculate the total observed energy consumption. Having matched each service to a schedule for which the distance covered was known, the energy consumption per train-km could be calculated in each case. Those services for which the number of valid energy readings was less than $90 \%$ of the expected number of readings were excluded. The proportion of the energy consumption attributable to the hotel load was calculated by multiplying an estimate of the hotel load in $\mathrm{kWh}$ per minute by the duration of the service.

Although it is useful to consider energy consumption for individual services, the total energy consumed by a train, including that consumed when idling or running empty, could be attributed to the service provision. To that end, the mean daily energy consumption divided by the mean daily distance travelled in passenger service was calculated for the fleet of intercity trains, for which more comprehensive data were available. This enabled some idea of how energy consumption and emissions should be scaled up to take account of idling and non-passenger running. 


\subsubsection{Estimating $\mathrm{CO}_{2}$ emissions}

$\mathrm{CO}_{2}$ emissions were estimated from the energy consumption data using the conversion factors suggested by DEFRA (2013a) for emissions from electricity generation in the $\mathrm{UK}$, including transmission losses. A figure of $490 \mathrm{~g}$ of $\mathrm{CO}_{2}$ per $\mathrm{kWh}$ consumed was used. This is marginally higher than the figure of $455 \mathrm{~g}$ of $\mathrm{CO}_{2}$ per $\mathrm{kWh}$ used by the RSSB for the year 2007 (RSSB, 2007), but this latter figure is at the point of generation, not consumption and therefore does not include transmission losses.

\section{Results}

\subsection{A breakdown of energy per train-km}

Figure 1 summarises the mean energy per train-km over all the passenger journeys sampled for each of the four trains analysed. The regen. energy is the energy returned to the grid via the regenerative braking system (where present). It has been possible to make an estimate of the size of the hotel load, with the remainder of the net energy assumed to be used to provide traction.

The effectiveness of regenerative braking is evident, with Suburban Train C and the Intercity Train each returning about $16 \%$ of gross energy consumed to the grid, and Suburban Train B returning 23\%. This is in line with other observations which suggest that 15 to $20 \%$ is typical, rising further for some inner suburban services (railwaygazette.com, 2012), and greater than the estimated savings cited by Network Rail (2009, Table 2.4), which were between 5\% and 9\% depending on the type of service. The mean distance between stops for services operated by Suburban Train B was found to be just $2.3 \mathrm{~km}$, which is much lower than those operated by Suburban Train A $(8.8 \mathrm{~km})$ and Suburban Train C $(12.2 \mathrm{~km})$. By separating the inner suburban services with a stop spacing of $10 \mathrm{~km}$ or less from the others, it was found that the 
proportion of energy regenerated by Suburban Train B rose to $20 \%$ with a mean stop spacing of $7.2 \mathrm{~km}$.

The estimated hotel load is observed to range from $6 \%$ of net energy consumption for Suburban Train A, up to $16 \%$ for Suburban Train B. In all cases, it is greater than the $5 \%$ of net energy consumption suggested by the RSSB (2011), and less than the $20 \%$ suggested by the International Union of Railways (UIC, 2003). The comparatively low hotel load for Suburban Train A is likely to reflect a lack of airconditioning and other on-board auxiliaries. It is postulated that the comparatively high hotel load for Suburban Train B is likely to reflect the high stopping density - the powered external doors will be operating frequently, and the heating system will be working harder due to a regular influx of cold air in to the passenger saloon. The latter point is particularly pertinent given that the data were recorded in the month of January.

\subsection{Variation of energy consumption between routes}

The variation in net energy consumption (in terms of kWh per train-km) of Suburban Train B over three different inner suburban routes given in Table 2 is shown graphically in Figure 2; outbound and return journeys are shown separately for each route.

Similarly, the variation in net energy consumption of the Intercity Train over the three different intercity routes is shown graphically in Figure 3.

It can be seen that there is greater variation for the suburban services than there is for the intercity services. One reason for this is thought to be that the suburban routes are much shorter, and so a particular change in gradient will have a much larger impact overall than over a longer intercity route where particular features of the infrastructure, such as changes in gradient become less significant overall. It is thought that the locations of some of the stops limit the possibility for coasting or cruising at reduced power on predominantly downhill routes. Although features of the infrastructure are 
still thought to play some role in the difference between the outbound and return services on an intercity route, it is also thought that timetabling - and the resulting amount of slack which can be used for coasting - plays some role.

Figure 4 shows how energy consumption (in terms of $\mathrm{kWh}$ per seat-km) varies with stopping density. It can be seen that the effect on intercity services is comparatively small because all services have a relatively low stopping density such that the time spent cruising at line speed remains the dominant factor. By contrast, the effect on inner suburban services is significant because all services have a high stopping density such that the time spent accelerating and decelerating is the dominant factor.

\subsection{The effect of non-passenger running and idling}

An additional estimation of the net energy consumption per train-km for the intercity fleet of trains was calculated by dividing the mean total daily energy consumption by the mean distance travelled in passenger service. This was found to be $14.4 \mathrm{kWh}$ per train-km, which is about $11 \%$ higher than the mean figure of $12.9 \mathrm{kWh}$ per train-km calculated for journeys in passenger service (Section 3.2.6). The additional energy consumption arises from empty running of the train to/from the depot, and from the fact that some power is typically supplied to the train at all times. This is to provide heating and lighting for cleaning and maintenance staff and to ensure that the carriages are at a comfortable temperature for the beginning of the duty cycle. These overheads are largely unique to rail; they do not apply to car travel in the same way. The provision of a coach service may necessitate some empty running to/from the depot, but the overall overheads are much lower, because buses are not typically left powered in the same way. For their case-study in the US, Chester \& Horvath (2009) consider "inactive operation", which includes the hotel load as well as non-passenger running and idling, and show that it is indeed less of a consideration for buses than it is for trains. 


\section{$4.4 \mathrm{CO}_{2}$ emissions}

Figure 5 shows the median $\mathrm{CO}_{2}$ emissions on a per seat-km basis for each of the trains analysed. It can be seen that Suburban Train C and the Intercity Train, which both have a much bigger mass per seat than the others (Table 1) have the biggest emissions. The type of service operated also has a role to play. The interquartile range, shown by the error bars, is largest for Suburban Train C, reflecting the fact that it is operated on both inner suburban and longer distance services. In percentage terms, the interquartile range represents between $14 \%$ and $17 \%$ of the median for the suburban trains and $11 \%$ of the median for the intercity train. This is thought to be partially influenced by the fact that the data set for the intercity train is much bigger, reducing the impact of outliers, but it is also thought to reflect the fact that stopping services have much more scope for differences in driving style, particularly in terms of rates of acceleration and braking, to be evident.

\section{Modal comparisons}

Figure 6 compares estimated $\mathrm{CO}_{2}$ emissions between different modes. The average data provided by DEFRA (Department for Environment Food and Rural Affairs, 2013a, 2013b), introduced in Section 2.1, are used as benchmarks. For passenger cars, the figure of $133.7 \mathrm{~g} \mathrm{CO}_{2}$ per vehicle-km was used (this applies to petrol cars; the average figure for diesel cars is similar, at $133.3 \mathrm{~g} \mathrm{CO}_{2}$ per vehicle-km). This was converted in to a figure of $83.6 \mathrm{~g} \mathrm{CO}_{2}$ per passenger-km, assuming an average occupancy level of 1.6 people (RSSB, 2007). For national rail, the single figure for diesel and electric rail combined is given as $48.8 \mathrm{~g} \mathrm{CO}_{2}$ per passenger-km, and for coach travel it is given as $28.7 \mathrm{~g} \mathrm{CO}_{2}$ per passenger-km. 
Figure 6 compares specific examples of each mode and illustrates how the emissions might be expected to vary with load factor. The range of the load factor for cars is limited by the requirement for a driver to occupy one seat (a load factor of $20 \%$ for the average five-seat car and $25 \%$ for four-seat cars such as the Chevrolet Volt) and the fact that (in Europe, at least), it is illegal to carry more passengers than there are seats. For public transport (coaches and trains), a load factor of $10 \%$ is assumed as a typical minimum, although services may operate with fewer passengers. For coaches, it is assumed that standing passengers are not allowed, leading to a maximum load factor of $100 \%$. Trains may normally carry more passengers than there are seats, and a typical maximum load factor of $110 \%$ is assumed (although some crush-laden commuter services may exceed that).

Two specific cars are chosen - the first is a five-seat Ford Focus 1.6 diesel, assumed to be representative of a typical family car, and the second is the Chevrolet Volt, a four-seat petrol-electric hybrid, given at the time of writing to produce the least emissions of any hybrid car (carpages.co.uk, 2013). Emissions data are based on official test-cycle figures from the online "Green Guide to $\mathrm{Car} \mathrm{CO}_{2}$ Emissions" (carpages.co.uk, 2013), and are uplifted to take in to account real-world effects, as discussed in Section 2.2.1. The uplift applied to the Ford Focus is 24\%, and the uplift applied to the Chevrolet Volt is $35 \%$, in line with the finding for similar models of Patterson et al. (2011). This gives figures of 135.2 and $35.5 \mathrm{~g} \mathrm{CO}_{2}$ per vehicle-km for the Ford and the Chevrolet respectively.

The data for diesel rail and coach travel are based on actual fuel consumption data presented by RSSB (2007), using a figure of $26.5 \mathrm{~g}$ of $\mathrm{CO}_{2}$ per litre of diesel per $100 \mathrm{~km}$. This gives $20.9 \mathrm{~g} \mathrm{CO}_{2}$ per seat-km for the Class 170 'Turbostar', $26.0 \mathrm{~g} \mathrm{CO}_{2}$ per seat-km for the Class 222 'Meridian' and $16.7 \mathrm{~g} \mathrm{CO}_{2}$ per seat-km for the 'Megabus' 
coach. Because the data for diesel rail are based on overall fuel consumption data, the assumption is made that they take in to account the effects of non-passenger running and idling.

Data for electric rail are calculated from the analysis in Section 3. They are based on the mean energy consumption calculated for each of the trains analysed, uplifted by $11 \%$ to take in to account non-passenger running and idling (Section 4.3). The calculated emissions figures range from $12.1 \mathrm{~g} \mathrm{CO}_{2}$ per seat-km for Suburban Train A through to $19.7 \mathrm{~g} \mathrm{CO}_{2}$ per seat-km for Suburban Train C.

\section{Discussion}

Figure 6 shows that modal comparisons are very dependent on assumptions made about passenger loadings. Although the DEFRA average figures suggest that rail might be expected to produce less $\mathrm{CO}_{2}$ per passenger-km than the car, it is clear that a full Ford Focus is comparable to a fairly full train, whilst a comparatively empty train could produce more emissions per passenger than a car with just the driver. Similarly, despite the gap suggested by DEFRA between coach travel and train travel, the 'Megabus' coach would appear to be broadly comparable to the Intercity Electric Train.

Furthermore, the Chevrolet Volt would appear to be the least polluting option overall, although there are some caveats to bear in mind. The manufacturer's data only measures tailpipe emissions and does not consider the electricity consumption associated with charging the battery or the fact that the benefits of the hybrid system are likely to be limited to a certain range; however, it does highlight what might happen should the motor industry continue to make progress in this area.

What Figure 6 does not show is how the emissions would be expected to be influenced by the type of journey being made. For example, the analysis in Section 3 has shown how different routes and services can impact the emissions of a train, and - 
for example - the emissions from a service with a high density of stops would be expected to be relatively high. This corroborates the RSSB's theory that the type of service operated is a key reason for the observed difference between two similar types of diesel train (Section 2.2.2). The possible impacts should be borne in mind, but caution should be taken when making comparisons based on a specific journey. The first reason for this is that single journeys are rarely made in isolation. In the case of public transport, providing a return journey along the same route is usually a necessary part of providing the service overall. Hence it would not be wise to consider outbound journeys without considering their return counterparts. The second reason for being cautious is that, as Section 4.3 shows, there are often significant operational overheads associated with running a train service, and by focussing entirely on individual journeys these can easily be ignored.

Figure 6 also makes the assumption that journeys made by different modes are directly comparable, when often they are not. Rail journeys are not point-to-point as car journeys usually are, and so extra consideration needs to be given to the trip to/from the station at each end. If this can be done on foot, there would be no impact on the overall carbon footprint. At the other end of the scale, someone being picked up and dropped off by car could lead to two return car trips being generated. Even if getting to/from the station has no significant effect, it cannot be assumed that the journey distance will be comparable by road and by rail.

The analysis here has also not taken 'life cycle' costs in to account. As has been shown elsewhere (for example, Baron, Martinetti, \& Pepion, 2011; Chester \& Horvath, 2009; Network Rail, 2009), the construction and maintenance of vehicles and infrastructure can consume significant amounts of energy and produce significant levels of GHG emissions. This can vary from mode to mode, with rail infrastructure often 
being more energy and carbon intensive than road infrastructure, although the construction of existing infrastructure could arguably be viewed as a sunk cost and discounted. It also needs to be borne in mind that the emissions figures for electric rail were calculated on the basis of the current UK electricity generation mix, which is still heavily reliant on fossil fuels. In 2011 , only $9.4 \%$ of UK electricity generated came from renewable sources, and although this rose to $11.2 \%$ in 2012 , the proportion of coal generators also increased, to the detriment of (cleaner) gas sources. A serious move away from fossil fuels towards cleaner electricity generation will reduce the emissions associated with electric rail.

Even if road and rail may appear comparable in terms of $\mathrm{CO}_{2}$ emissions, the wider benefits of rail travel should not be ignored. For example, unlike cars and buses powered by internal combustion engines, electric trains do not produce emissions at the point of use, and the noise levels may be lower than alternative modes. This can be beneficial for air quality, particularly in urban areas, whilst trains can help to reduce problems associated with road congestion - if everyone who currently travelled by train decided to drive instead, there would be a large increase in the volume of traffic at key points.

For travellers considering alternatives to the car, rail may also be more attractive than other options, such as coach travel. Intercity trains are often faster than coaches, and the on-board environment may be better than that of a coach for enticing people out of their cars. Many coach operators do now offer free Wifi, but long distance trains generally provide a better working environment. The design of the on-board environment, however, can involve trade-offs. For example, provision of lower density seating and other amenities to attract modal shift can increase the mass per seat and 
reduce the number of passengers carried, thereby increasing the emissions per passenger.

It can also be easy to become fixed on the idea that higher passenger occupancy levels, and the resulting reductions in emissions per passenger-km for a given journey are always beneficial, but this will not be the case if the extra passengers are as a result of trip generation rather than modal shift from more polluting modes. Even if the mass of a few extra passengers on a train does not result in an appreciable increase in energy consumption and emissions for the train journey itself, there are additional costs associated with trip generation, such as any emissions generated by getting to and from the station. For this reason, if modal shift towards rail is to be encouraged, the policy instruments used to do this must be chosen with care. Wee, Janse, \& Brink (2005) suggest that positive moves alone, such as reducing rail fares or increasing the speed of the trains, will generate more new rail passengers than the number of people who switch from the car to the train. To avoid this, a combination of measures, which also include those which reduce the attractiveness of the car (such as parking policies) could be used.

It is also worth noting that when seeking a reduction in energy consumption and emissions, it is not the modal shift itself which is important, but the resulting level of vehicle trip cancellation. If a car journey was less polluting per passenger, there would only be a net benefit if the alternative public transport was cancelled - otherwise, choosing to drive would only add to the overall emissions. However, cancelling those rail journeys which are deemed to be uncompetitive in terms of energy and emissions should be done with caution, as they may be an integral part of a wider system which brings overall benefits.

\section{Conclusions}

Analysing metered data from specific trains has demonstrated how different trains and 
different services can vary from an overall average figure, supporting in principle the RSSB's statement that data for mixed service types may be of little value. Analysis of different service types corroborated the theory that emissions figures for specific types of train can be heavily influenced by operational patterns. However, comparing data for a single route alone may equally be of little value and the importance of including energy consumption not directly attributable to passenger running has also been seen.

Understanding some of the reasons for variation between different trains and routes has been, and could continue to be, important in the drive to reduce energy consumption and emissions. For example, the importance of regenerative braking, and the potential savings from more efficient on-board heating and lighting are clear.

When it comes to making modal comparisons, electric rail performs better than diesel rail, but even so there are suggestions that the gap between road and rail transport may be quite narrow. However, it is arguably counter-productive to encourage people not to utilise services which will be run anyway - it is absolutely right to plan for the future and to understand if and in what circumstances promotion of rail services can contribute to a reduction in overall emissions, but in current circumstances the best policy is to increase the load factor on rail services and not to encourage additional car trips.

\section{References}

Armstrong, J., \& Preston, J. (2010). Rail in the context of climate change: strengths, weaknesses, opportunities and threats. In Proceedings from the 12th World Conference on Transport Research, Lisbon.

Banister, D. (2010). Cities, Mobility, and Climate Change. In Proceedings from the 12th World Conference on Transport Research, Lisbon (Vol. 11).

Baron, T., Martinetti, G., \& Pepion, D. (2011). Carbon footprint of high speed rail. Retrieved from http://trid.trb.org/view.aspx?id=1134978 
carpages.co.uk. (2013). The Green Guide to Car CO2 Emissions. Retrieved November 05, 2013, from http://www.carpages.co.uk/co2/

Chester, M., \& Horvath, A. (2009). Environmental assessment of passenger transportation should include infrastructure and supply chains. Environmental Research Letters, 4(2), 024008. doi:10.1088/1748-9326/4/2/024008

Department for Environment Food and Rural Affairs. (2010). 2010 Guidelines to Defra / DECC's GHG Conversion Factors for Company Reporting. defra. Retrieved from http://archive.defra.gov.uk/environment/business/reporting/pdf/101006-guidelinesghg-conversion-factors.xls

Department for Environment Food and Rural Affairs. (2013a). 2013 GHG Conversion Factors (Complete Offline DataSet). Retrieved from http://www.ukconversionfactorscarbonsmart.co.uk/

Department for Environment Food and Rural Affairs. (2013b). 2013 Government GHG Conversion Factors for Company Reporting : Methodology Paper for Emission Factors. Retrieved from https://www.gov.uk/government/uploads/system/uploads/attachment_data/file/224 437/pb13988-emission-factor-methodology-130719.pdf

Department for Transport. (2009). Factsheets - UK Transport and Climate Change Data. Retrieved from http://www.dft.gov.uk/pgr/statistics/datatablespublications/energyenvironment/cli matechangefactsheets.pdf

Department for Transport. (2011). Transport energy and environment statistics 2011. Retrieved from https://www.gov.uk/government/uploads/system/uploads/attachment_data/file/894 7/energy-2011.pdf

Department for Transport. (2013). National Travel Survey: 2012. Retrieved from https://www.gov.uk/government/uploads/system/uploads/attachment_data/file/243 957/nts2012-01.pdf

Department of Energy \& Climate Change. (2011). Digest of United Kingdon Energy Statistics 2011. London. Retrieved from http://www.decc.gov.uk/assets/decc/11/stats/publications/dukes/2312-dukes-2011-full-document-excluding-cover-pages.pdf

European Environment Agency. (2010). Occupancy rates of passenger vehicles (TERM 029) - Data Set. Retrieved from http://www.eea.europa.eu/data-andmaps/figures/term29-occupancy-rates-in-passenger-transport-1/2009-29occupancy-rates-of-passenger.xls/at_download/file

HM Government. (2011). The Carbon Plan: Delivering our low carbon future. Retrieved from https://www.gov.uk/government/uploads/system/uploads/attachment_data/file/476 13/3702-the-carbon-plan-delivering-our-low-carbon-future.pdf 
Hobson, M., \& Smith, A. (2001). Rail Emission Model - Final Report. Retrieved from http://s3.amazonaws.com/zanran_storage/www.dft.gov.uk/ContentPages/2354166. pdf

Mock, P., German, J., Bandivadekar, A., \& Riemersma, I. (2012). Discrepancies between type-approval and "real-world" fuel-consumption and CO2 values (No. 2012-02). Retrieved from http://www.theicct.org/sites/default/files/publications/ICCT_EU_fuelconsumption 2_workingpaper_2012.pdf

Network Rail. (2007). Common Interface File - End User Specification.

Network Rail. (2009). Comparing environmental impact of conventional and high speed rail. Retrieved from http://www.networkrail.co.uk/documents/About us/New Lines Programme/5878_Comparing environmental impact of conventional and high speed rail.pdf

Network Rail. (2012). Extracts from Network Rail Timetable Database.

Network Rail. (2013). Network Rail proposal : Auditing and re-calibrating on-train energy measurement systems. Retrieved from http://www.networkrail.co.uk/WorkArea/DownloadAsset.aspx?id=30064786029

Office of Rail Regulation. (2011). National Rail Trends 2010-11 Yearbook. Retrieved from http://www.rail-reg.gov.uk/upload/pdf/nrt-yearbook-2010-11.pdf

Patterson, J., Alexander, M., \& Gurr, A. (2011). Preparing for a Life Cycle CO2 Measure. Retrieved from http://www.lowcvp.org.uk/assets/reports/RD11_124801_5 - LowCVP - Life Cycle $\mathrm{CO} 2$ Measure - Final Report.pdf

railwaygazette.com. (2012). DMUs to test regenerative braking. Railway Gazette. Retrieved February 01, 2014, from http://www.railwaygazette.com/news/business/single-view/view/dmus-to-testregenerative-braking.html

RSSB. (2007). Traction Energy Metrics. Retrieved from http://www.rssb.co.uk/SiteCollectionDocuments/pdf/reports/research/T618_tractio n-energy-metrics_final.pdf

RSSB. (2011). Meeting Rail's Carbon Ambition. Retrieved from http://www.rssb.co.uk/NP/SRP/Documents/Meeting rail's carbon ambition.pdf

ShareGeo. (2010). GB Transportation Network (1:50 000 Meridian 2). Retrieved from http://www.sharegeo.ac.uk/handle/10672/49

SMMT. (2013). New Car CO2 Report 2013 The 12th report. Retrieved from http://www.smmt.co.uk/wp-content/uploads/sites/2/SMMT-New-Car-CO2-Report2013-web.pdf 
swlines Ltd. (2012). TIPLOC Mileage Data.

UIC. (2003). EVENT Evaluation of Energy Efficiency Technologies for Rolling Stock and Train Operation of Railways. Retrieved from http://scholar.google.com/scholar?hl=en\&btnG=Search\&q=intitle:Evaluation+of+ Energy+Efficiency+Technologies+for+Rolling+Stock+and+Train+Operation+of+ Railways\#0

Weather Underground Inc. (2013). www.wunderground.com. Retrieved September 20, 2013, from http://www.wunderground.com/

Wee, B. Van, Janse, P., \& Brink, R. Van Den. (2005). Comparing energy use and environmental performance of land transport modes. Transport Reviews, 25(1), $3-$ 24. doi:10.1080/014416410001676861 


\section{Tables}

Table 1: A summary of the trains analysed here

\begin{tabular}{|c|c|c|c|c|}
\hline Train & Train details & Services operated & $\begin{array}{l}\text { Typical \# } \\
\text { of seats }\end{array}$ & $\begin{array}{l}\text { Typical mass } \\
\text { per seat }(\mathrm{t})\end{array}$ \\
\hline $\begin{array}{l}\text { Suburban } \\
\text { Electric A }\end{array}$ & $\begin{array}{l}\text { Max. Speed } 161 \mathrm{~km} / \mathrm{h} \\
(100 \mathrm{mph}) \\
\text { Not equipped with air- } \\
\text { conditioning or } \\
\text { regenerative braking. }\end{array}$ & $\begin{array}{l}\text { Limited range of outer- } \\
\text { suburban services }\end{array}$ & 299 & 0.5 \\
\hline $\begin{array}{l}\text { Suburban } \\
\text { Electric B }\end{array}$ & $\begin{array}{l}\text { Max. Speed } 145 \mathrm{~km} / \mathrm{h} \\
(90 \mathrm{mph}) \\
\text { Equipped with } \\
\text { regenerative braking but } \\
\text { not air-conditioning. }\end{array}$ & $\begin{array}{l}\text { Inner-suburban services } \\
\text { with less than } 10 \mathrm{~km} \\
\text { between stops }\end{array}$ & 283 & 0.4 \\
\hline $\begin{array}{l}\text { Suburban } \\
\text { Electric C }\end{array}$ & $\begin{array}{l}\text { Max. Speed } 161 \mathrm{~km} / \mathrm{h} \\
(100 \mathrm{mph}) \text {. } \\
\text { Equipped with both } \\
\text { regenerative braking and } \\
\text { air-conditioning. }\end{array}$ & $\begin{array}{l}\text { A mixture of inner- } \\
\text { suburban services with } \\
\text { less than } 10 \mathrm{~km} \text { between } \\
\text { stops and longer } \\
\text { distance outer-suburban } \\
\text { and inter-urban services }\end{array}$ & 183 & 1.0 \\
\hline $\begin{array}{l}\text { Intercity } \\
\text { Electric }\end{array}$ & $\begin{array}{l}\text { Max. Speed } 201 \mathrm{~km} / \mathrm{h} \\
(125 \mathrm{mph}) . \\
\text { Equipped with } \\
\text { regenerative braking, air- }\end{array}$ & $\begin{array}{l}\text { Intercity services, } \\
\text { typically with more } \\
\text { than } 50 \mathrm{~km} \text { between } \\
\text { stops }\end{array}$ & 439 & 1.1 \\
\hline
\end{tabular}




\begin{tabular}{|l|l|l|l|l|}
\hline & conditioning, power & & \\
sockets for laptops and on- & & & \\
board catering facilities. & & & \\
\hline
\end{tabular}

Table 2 - Characteristics of selected routes

\begin{tabular}{|l|l|l|}
\hline Route & Route Length $(\mathbf{k m})$ & Mean Stop Spacing (km) \\
\hline Suburban Route 1 & 12.7 & 1.7 \\
\hline Suburban Route 2 & 20.7 & 2.9 \\
\hline Suburban Route 3 & 13.2 & 3.2 \\
\hline Intercity Route 1 & 206 & 25.7 \\
\hline Intercity Route 2 & 181 & 45.3 \\
\hline Intercity Route 3 & 295 & 73.7 \\
\hline
\end{tabular}

\section{List of Figures}

Figure 1: A breakdown of the energy consumption for the trains analysed

Figure 2: Variation in energy consumption for selected inner suburban routes (Suburban Train B)

Figure 3: Variation in energy consumption for selected intercity routes

Figure 4: The variation in energy consumption with mean stop spacing

Figure 5: Carbon-dioxide emissions per seat-km

Figure 6: A comparison of emissions per passenger-km for different modes, showing variation with load factor 
